\title{
DESIGN AND SIMULATION OF NEURON-EQUIVALENTORS ARRAY FOR CREATION OF SELF-LEARNING EQUIVALENT-CONVOLUTIONAL NEURAL STRUCTURES (SLECNS)
}

\begin{abstract}
In the paper, we consider the urgent need to create highly efficient hardware accelerators for machine learning algorithms, including convolutional and deep neural networks (CNN and DNNS), for associative memory models, clustering, and pattern recognition. We show a brief overview of our related works the advantages of the equivalent models (EM) for describing and designing bio-inspired systems. The capacity of NN on the basis of EM and of its modifications is in several times quantity of neurons. Such neural paradigms are very perspective for processing, clustering, recognition, storing large size, strongly correlated, highly noised images and creating of uncontrolled learning machine. And since the basic operational functional nodes of EM are such vector-matrix or matrix-tensor procedures with continuous-logical operations as: normalized vector operations "equivalence", "nonequivalence", and etc. , we consider in this paper new conceptual approaches to the design of full-scale arrays of such neuron-equivalentors (NEs) with extended functionality, including different activation functions. Our approach is based on the use of analog and mixed (with special coding) methods for implementing the required operations, building NEs (with number of synapsis from 8 up to 128 and more) and their base cells, nodes based on photosensitive elements and CMOS current mirrors. Simulation results show that the efficiency of NEs relative to the energy intensity is estimated at a value of not less than $10^{12} \mathrm{an}$. op. / sec on $W$ and can be increased. The results confirm the correctness of the concept and the possibility of creating NE and MIMO structures on their basis.

Keywords: Neuron-Equivalentor, Hardware Accelerator, Self-Learning Equivalent-Convolutional Neural Structures,
\end{abstract} continuous logic, current mirror.

В. Г. КРАСИЛЕНКО, Н. П. ЮРЧУК Вінницький національний аграрний університет Д. В. НІКІТОВИЧ

Вінницький національний технічний університет

\section{ПРОЕКТУВАННЯ ТА МОДЕЛЮВАННЯ МАСИВУ НЕЙРОН-ЕКВІВАЛЕНТОРІВ ДЛЯ СТВОРЕННЯ САМОНАВЧАЛЬНИХ ЕКВІВАЛЕНТНО-ЗГОРТКОВИХ НЕЙРОННИХ СТРУКТУР (СНЕЗНС)}

у статті ми розглядаємо гостру необхідність створення високоефективних апаратних прискорювачів для алгоритмів машинного навчання, включаючи згорткові і глибокі нейронні мережі (ЗНМ і ГЗНМ), для моделей асоціативноі пам'яті, кластеризаціі та розпізнавання образів. Ми показуємо в короткому огляді наших пов'язаних робіт переваги еквівалентністних моделей (ЕМ) для опису і проектування біо-натхненних систем. Ємність НМ на основі ЕМ і її модифікацій в кілька разів перевищує кількість нейронів. Такі нейронні парадигми дуже перспективні для обробки, кластеризації, розпізнавання, зберігання сильно корельованих і зашумлених зображень навіть великого розміру і для створення неконтрольованої навчальної машини. Базовими операційними функціональними вузлами ЕМ є векторно-матричні або матрично-тензорні процедури з такими безперервно-логічними операціями, як: нормалізовані векторні операції «еквівалентність», «нееквівалентність». Ми розглядаємо в цій статті нові концептуальні підходи до створення повномасштабних масивів таких нейрон-еквіваленторів (НЕ) з розширеними функціональними можливостями, включаючи різні функції активації. Наш підхід заснований на використанні аналогових і змішаних (із спеціальним кодуванням) методів реалізації необхідних операцій, побудови мережевих елементів (з числом синапсів від 8 до 128 і більше) і їх базових елементів, вузлів та модулів на основі світлочутливих елементів $і$ відбивачів струму (струмових дзеркал) на CMOS. Результати моделювання показують, що відносна енергоефективність НЕ оцінюється величиною не менше $10^{\wedge} 12$ ан. ор. / сек на Вт і може бути збільшена. Результати підтверджують правильність концепції і можливість створення на їх основі структур НЕ і СНЕЗНС.

Ключові слова: нейрон-еквівалентор, апаратний прискорювач, самонавчальні еквівалентністно-згорткові нейронні структури, неперервна логіка, струмове дзеркало.

\section{Introduction}

For many applications applied in the creation of biometric systems, machine vision systems are necessary to solve the problem of object recognition in images. The basis of most known methods and algorithms is to compare two different images of the same object or its fragment. Discriminant measure of the mutual alignment reference fragment with the current image, the coordinate offset is often a mutual two-dimensional correlation function. In paper [1-3] it was shown, that to improve accuracy and probability indicators with strong correlation noise-damaged image, it is desirable to use recognition methods based on mutual equivalently 2D spatial functions, nonlinear transformations and adaptive-correlation weighting. For the recognition and clustering of images, various models of neural networks are also used. Models of equivalence (EM) of auto-associative memory (AAM) and hetero-associative memory (HAM) were proposed [2-6]. Investigations of AAM and HAM using EMs have shown, that these advanced equivalence models allow the recognition of vectors with 1024-4096 components and a significant percentage (up to 25-30\%) of damage, at a network power that is 3 to 4 times higher than the number of neurons $[3,5,6]$. For of analysis and recognition should be solved the problem of clustering of objects. This previous clustering allows organizing proper automated grouping data, to cluster analysis, to evaluate on the basis of many signs each cluster, put a class label and improved subsequent learning procedures and classification. At the 
same time, knowing the significant advantages of EM when creating on their basis improved neural networks (NNs), multiport AAM and HAM, there was a suggestion about the possibility of modifying EM and MHAM for parallel clustered image analysis [6-8]. At the same time, an urgent task is to study a more general, spatially invariant (SI) equivalence models (SI EMs) that is more invariant to spatial displacements and the possibilities of its application for image clustering [7-9]. And the latter are basic operations in the most promising paradigms of convolutional neural networks $(\mathrm{CNN})$ with deep learning $[8,9]$. In our previous paper [8] questions of new possible ways of selflearning in such advanced models, explaining some important fundamental concepts of diverse associative recognition and understand the principles of the functioning of biological NN structures, perform modeling of processing processes, training and extraction of regularities in such models, and propose their implementation were considered. These questions were considered for binary-maps of multi-level images.

In paper [9] we showed that the self-learning concept works with directly multi-level images without processing of the binary-maps. In SI EM, we compute the spatially dependent normalized equivalence functions (SD_NEF) whose elements will correspond to the value of the normalized equivalence of the fragment of the input image $X$ and one of the selected fragments from the training matrix. For implementation SLECNS [9], we need certain new or modified known devices capable of calculating normalized spatial equivalence functions (NSEqFs) with the necessary speed and performance. Such specialized devices by authors of papers were previously called "image equivalentor". There are known connections of equivalent functions with correlation functions that make it possible to calculate NSEqFs. Thus, the image equivalentor is itself a doubled correlator or a doubled convolver. In paper $[8,9]$ we showed models for the recognition and clustering of images that combine the process of recognition with the learning process. For all known convolutional neural networks, as for our equivalence models, it is necessary to calculate the convolution of the current fragment of the image in each layer with a large number of templates which are used, selected or formed during the learning process. But, as studies show, large images require a large number of filters to process images, and the size of the filters can also be large. Therefore, the problem of increasing the computing performance of hardware implementations of such CNNs and SLECNS is acute. It should be noted that the accuracy of calculations, especially for large filter sizes and a large dynamic range (8 bits) of halftone images, is required to make the correct decisions when determining neuron-winners. The last decade was marked by the activation of works aimed at the creation of specialized neural accelerators, which compute the function of comparing two 2D arrays and using the operations of multiplication and addition-accumulation. But, as our experiments show, our models allow not only creating advanced SLECNS, but also faster and more compact arrays of equivalentor-neurons, which are so necessary as accelerators.

Formulation of the problem and goal of the work

Therefore, in this paper, using our approaches to designing one-dimensional neuron-equivalentors, we consider the structure of the neuron-equivalentors, generalized for processing 2D arrays.

\section{Presentation of the main material, research results}

Brief review and background of mathematical operators, which are implemented by neurons.

Almost all concepts, models, structures of neural networks use informational mathematical models of neurons, which are reduced to the presence of two basic mathematical components-operators: the first component computes a function from two vectors $\vec{X}$ and $\vec{W}$, where $\vec{X}$ - vector of input signals of a neuron, $\vec{W}-$ vector of weights, and the second component corresponds to some nonlinear transformation of the output value of the first component to the output signal. The input operator can be implemented as the following expressions [10-13].

$$
\begin{aligned}
& \text { - sum of the self-weighted inputs } f(\overrightarrow{X,}, \vec{W})=\sum_{i=1}^{N} w_{i} x_{i} ; \\
& \text { - maximal value of the self-weighted inputs } f(\overrightarrow{X, W})=\max _{i}\left(w_{i} x_{i}\right) ; \\
& \text { - product of the self-weighted inputs } f(\overrightarrow{X, W})=\prod_{i=1}^{N} w_{i} x_{i} ; \\
& \text { - minimum value of the self-weighted inputs } f(\vec{X}, \vec{W})=\min _{i}\left(w_{i} x_{i}\right)
\end{aligned}
$$

But lately the set of such operators broadened substantially [10-13]. For example appearance of equivalency models of neural networks which possess some advantages, requires a calculation and such below resulted operators:

- normalized equivalence of vectors:

$$
\begin{aligned}
& \text { a) } f(\vec{X}, \vec{W})=\dot{\tilde{e}}(\vec{X}, \vec{W})=\frac{1}{N} \sum_{i=1}^{N}\left(x_{i} \dot{\sim} w_{i}\right)=\frac{1}{N} \sum_{i=1}^{N}\left(x_{i} w_{i}+\left(1-x_{i}\right)\left(1-w_{i}\right)\right) \\
& \text { b) } f(\vec{X}, \vec{W})=\frac{1}{N} \sum_{i=1}^{N}\left(1-\left|x_{i}-w_{i}\right|\right)=\dot{\sim}(\vec{X}, \vec{W}) ; \\
& \text { c) } f(\vec{X}, \vec{W})=\frac{1}{N} \sum_{i=1}^{N}\left(x_{i} \sim w_{i}\right)=\frac{1}{N} \sum_{i=1}^{N}\left(x_{i} \wedge w_{i} \vee \bar{x}_{i} \wedge \bar{w}_{i}\right)=\stackrel{\sim}{e}(\vec{X}, \vec{W}) ;
\end{aligned}
$$


- normalized nonequivalence of vectors:

$$
\begin{aligned}
& \text { a) } f(\overrightarrow{X, W})=\dot{\sim}(\overrightarrow{X,} \vec{W})=\frac{1}{N} \sum_{i=1}^{N}\left(x_{i}+w_{i}\right)=\frac{1}{N} \sum_{i=1}^{N}\left(x_{i} \bar{w}_{i}+\bar{x}_{i} w_{i}\right) \\
& \text { b) } f(\vec{X}, \vec{W})=\stackrel{+}{\sim}(\vec{X}, \vec{W})=\frac{1}{N} \sum_{i=1}^{N}\left|x_{i}-w_{i}\right|=\frac{1}{N} \sum_{i=1}^{N}\left(1-x_{i} \wedge w_{i}-\bar{x}_{i} \wedge \bar{w}_{i}\right) \text {; } \\
& f(\overrightarrow{X, \vec{W}})=\frac{1}{N} \sum_{i=1}^{N}\left(x_{i} \stackrel{\vee}{\nsim} w_{i}\right)=\stackrel{\sim}{n} e(\vec{X}, \vec{W})=\frac{1}{N} \sum_{i=1}^{N}\left(\left(x_{i} \wedge \bar{w}_{i}\right) \vee\left(\bar{x}_{i} \wedge w_{i}\right)\right.
\end{aligned}
$$

Because we consider how to realize these input operators. We examine a case, when components of vectors $\vec{X}$ and $\vec{W}$ (nonequivalence), but time-pulse coding was used for analog signals. The simulation was performed only for small dimensions of the input vectors with a calculation time of $100 \mu \mathrm{s}$. In addition, the activation functions were not simulated and shown. The positive aspect of that work was the use of a modular principle that allowed the calculation of the operator of the normalized equivalence of a vector to the calculation of normalized equivalent subvectors and their output signals. In paper [14] the mathematical basis of creation of neurons of equivalents calculating the function of normalized equivalence is described in detail, using the modular principle. It shows that all algorithmic procedures in the equivalence paradigm of neural networks and hetero-associative memory on their basis are reduced to the calculation of normalized equivalences from two vectors or matrices, and the elemental nonlinear transformations of transformations that correspond to the activation functions, and for the above equivalence models of neural networks, reduce to the calculation of auto-equivalences (auto-non-equivalences). Consider the structural design, using the approaches in [14].

Let vectors $\vec{X}$ and $\vec{W}$ have dimension $N=k \cdot Q$. For every $i$-th $(i \in 1 \div k)$ subvector $\vec{X}_{i}$ and $i$ subvector $\vec{W}_{i}$, the dimension of which equal to $Q$, it is possible to calculate $f_{i}\left(\overrightarrow{x_{i}}, \overrightarrow{w_{i}}\right)=\frac{1}{Q} \sum_{l=1}^{Q}\left(x_{i}^{l} \sim w_{i}^{l}\right)=\tilde{e}_{i}\left(\overrightarrow{x_{i}}, \overrightarrow{w_{i}}\right)$. Then it is possible to show that: $f(\vec{x}, \vec{w})=\frac{1}{k} \sum_{i=1}^{k} f_{i}\left(\vec{x}_{i}, \vec{w}_{i}\right)=\frac{1}{k} \sum_{i=1}^{k}\left(f_{i} \sim 1\right)=\tilde{e}\left(\vec{f}_{k}, \overrightarrow{1}_{k}\right)$, where $\vec{f}_{k}$ and $\overrightarrow{1}_{k}$ are vectors of K dimension, the components of which are equal $f_{i}$ and "1" accordingly. Like: $\bar{f}(\vec{x}, \vec{w})=\tilde{n} e\left(\vec{f}^{k}, \overrightarrow{0}^{k}\right)$. Hence, for increase of vectors dimension, given at inputs of our complementary-dual NE (CDNE), it is possible to use base analogical CDNE of less dimension. Easily to see that by changing the tuning vector the second stage can works as neuron-equivalentor $(\mathrm{NEq})$, neuron-nonequivalentor $(\mathrm{NnEq})$ or dual neuron-equivalentor $(\mathrm{DNEq})$. If an element has two outputs, thus on the first output $f$ or $\tilde{e}$, and on the second $-\bar{f}$ or $n \tilde{e}$, by changing tuning vector at the same input vectors on the first output in place of $f$ it will be $\bar{f}(\tilde{n e})$, and on the second $-f(\tilde{e})$.

It substantially extends functional possibilities of such base CDNE, especially at their association in more difficult hierarchical structures. It consists of $\mathrm{N}$ blocks which execute a scalar operation ( ${ }^{\dagger}$ ) nonequivalence of $i$-th component of vectors $\vec{x}^{k}$ and $\vec{w}^{k}$, for example: $\left(x_{i}+w_{i}\right)=\left|x_{i}-w_{i}\right|=\max \left(x_{i}, w_{i}\right)-\min \left(x_{i}, w_{i}\right)$. It is needed to have a block of subtraction of currents and adder-normalizer only, whether adders and block of subtraction. That we realize circuit after formulas:

$$
\tilde{n e}(\vec{x}, \vec{w})=\frac{1}{N} \sum_{i=1}^{n} \max _{i}\left(x_{i,} w_{i}\right)-\frac{1}{N} \sum_{i=1}^{n} \min _{i}\left(x_{i,} w_{i}\right)=\sum_{i=1}^{N}\left(\frac{\max \left(x_{i}, w_{i}\right)-\min \left(x_{i,} w_{i}\right)}{N}\right)
$$

To realize the operation of $f$ or $\tilde{e}(\vec{x}, \vec{w})$ it is possible also to use formulas:

$$
\tilde{e}(\vec{x}, \vec{w})=\frac{1}{N} \sum_{i=1}^{N}\left(1+\min _{i}\left(x_{i}, w_{i}\right)\right)-\frac{1}{N} \sum_{i=1}^{N} \max _{i}\left(x_{i}, w_{i}\right)=1-\frac{1}{N} \sum_{i=1}^{N} \max _{i}+\frac{1}{N} \sum_{i=1}^{N} \min _{i}
$$

We will note that on a current mirror more easily to execute these operations of addition or subtraction of currents. The experiments in work [9] show great promise of the proposed methods and models of self-learningrecognition of images, including multilevel images. But for their work in real time, taking into account the large requirements for performance and the amount of calculations, it is necessary to have appropriate high-performance and energy-efficient arrays with parallel principles of operation and picture input-outputs, whose design was 
partially considered in papers [15-22]. And here we will offer a new structure. For all known CNNs, as for our equivalence models, it is necessary to calculate the convolution of the current fragment of the image in each layer with a large number of templates that are used, which are a set of standards that are selected or formed during the learning process. But, as studies show, large images require a large number of filters to process images, and the size of the filters can also be large.

Therefore, the problem of increasing the computing performance of hardware implementations of such CNNs is acute. It should be noted that the accuracy of calculations, especially for large filter sizes and a large dynamic range of halftone images, is required to make the correct decisions when determining neuron-winners. The last decade was marked by the activation of works aimed at the creation of accelerators, which compute the function of comparing two 2D arrays and using the operations of multiplication and addition-accumulation.

Unlike most papers, in our works we use those functions of normalized equivalence in which there is no multiplication operation. But as our experiments show, equivalent models also allow the construction of equivalence convolutional structures and self-learning systems. Therefore, in this paper, using our approaches to designing onedimensional neuron-equivalents, we consider the structure of the neuron-equivalent, generalized for processing $2 \mathrm{D}$ arrays.

The Fig. 1 shows the block diagram of the main unit of SLECNS. The matrix $\mathbf{X}$ forms a certain number of convolutions in the form of matrices e using a set of defined filters-templates $\mathbf{W}$ which, in our case, are multilevel values, in contrast to the binary ones we used earlier. Thus, we compare each filter with a current fragment in the matrix $\mathbf{X}$. As a measure of the similarity of the fragment of the matrix $\mathbf{X}$ and the filter the equivalent measures of proximity or other measures such as a histogram can be used.

Thus, we compare for each filter similar fragments in the matrix. Fig. 1 shows the new structure of our proposed system, allowing parallel, with a high rate, equal to the speed of selection from the processed image of its shifted current fragment, to compute a set of stream components (elements) immediately one-cycle all the equivalents convolutions of the current fragment with the corresponding filters. It consists of a micro-display dynamically displaying current fragments, an optical node in the form of a micro-lens array (MLA) with optical lenses (not shown!) and a 2D array of neuron-equivalentors (NEqs) with optical inputs. Each NEq is implemented in a modular hierarchical manner and can consist of similar smaller sub-pixel, also 2D type, base nodes.

The NEq has a matrix (ruler) of photo-detectors, on which a halftone image of the fragment is projected through the microlens array (MLA), and the number of electrical analog inputs equal to the number (number) of photo-detectors, to which by means of any known method: from the sample and hold device (SHD), from the analog memory, with subsequent conversion using a set of DACs, etc. the filter components are fed. These components are represented in the form of microcurrents. Each NEq has its own filter mask from a set of filters selected or formed by training.

Thus, at the inputs of each NEq we have two arrays (vectors) of analog currents representing the compared current fragment and the corresponding filter-standard, and the output of the NEq is an analog current signal, nonlinearly transformed in accordance with the activation function and representing some measure of their similarity, proximity). In our case, this measure is a normalized equivalence (eq) and nonequivalence (neq), we can calculate them by averaging the component maxima and minima currents.

Therefore, the base node, see Fig. 2, contains $\mathrm{N}$ two input counters of maximum and minimum currents and one normalizer on current mirrors, which forms two output signals corresponding to normalized eq and neq from two N-component vectors.

The basic unit for calculating the normalized Eq (NEq) by averaging the component maximal and minimal of currents on the basis of current mirrors and the schemes of the limited difference is shown in Fig. 2. Sources of analog currents are shown as current generators for modeling in OrCAD. The dimension of the vector inputs is 9, which corresponds to the filter size $3 \times 3$. The results of modeling this basic unit with a nonlinear transformation are shown in Fig. 3-5, 7.

At the instants of $11-12 \mu \mathrm{s}$ and $13-14 \mu \mathrm{s}$, the output signals of equivalence and nonequivalence testify to the coincidence of the input vectors (Fig. 3-5). The results of modeling the base unit for the filter size $3 \times 3$ (with 9 inputs) showed, that processing time is from $1 \mu$ s to $0.1 \mu$ s for currents Imax $=5 \mu \mathrm{A}$, consumption power is from $200 \mu \mathrm{W}$ to $50 \mu \mathrm{W}$.

In addition to simulating the base node on 9 inputs, we additionally synthesized a neuron-equivalentor circuit having 8 such nodes, each of which compares 8 input vectors, resulting in a neural element circuit having 2 vector inputs of 64 dimensions. For a non-linear transformation, we used a node whose circuit is shown in Fig. 6 , which realizes a piecewise linear approximation of the power-law activation function (auto-equivalence). The results of simulating such 64 input NE with nonlinear conversion of the output signal-response for linearly rising (falling) currents with a period $\mathrm{T}=2.5 \mu$ s are shown in Fig. 8,10 .

In the same place, the results of modeling the formation processes of linear and nonlinear normalized neq are shown. Experiments have shown that such a NE comparing two 64-component vectors from current signals provides good time characteristics and has a total power consumption of approximately 2-3 mW, a low supply voltage, contains less than 1000 CMOS transistors which execute summation, limited subtraction and multiplication of analog currents on current mirrors.

By simple build-up of units and additional inputs of level-matching (Fig. 9) normalizers, our trip allows us to increase the number of inputs and increase the dimension of the filters. 

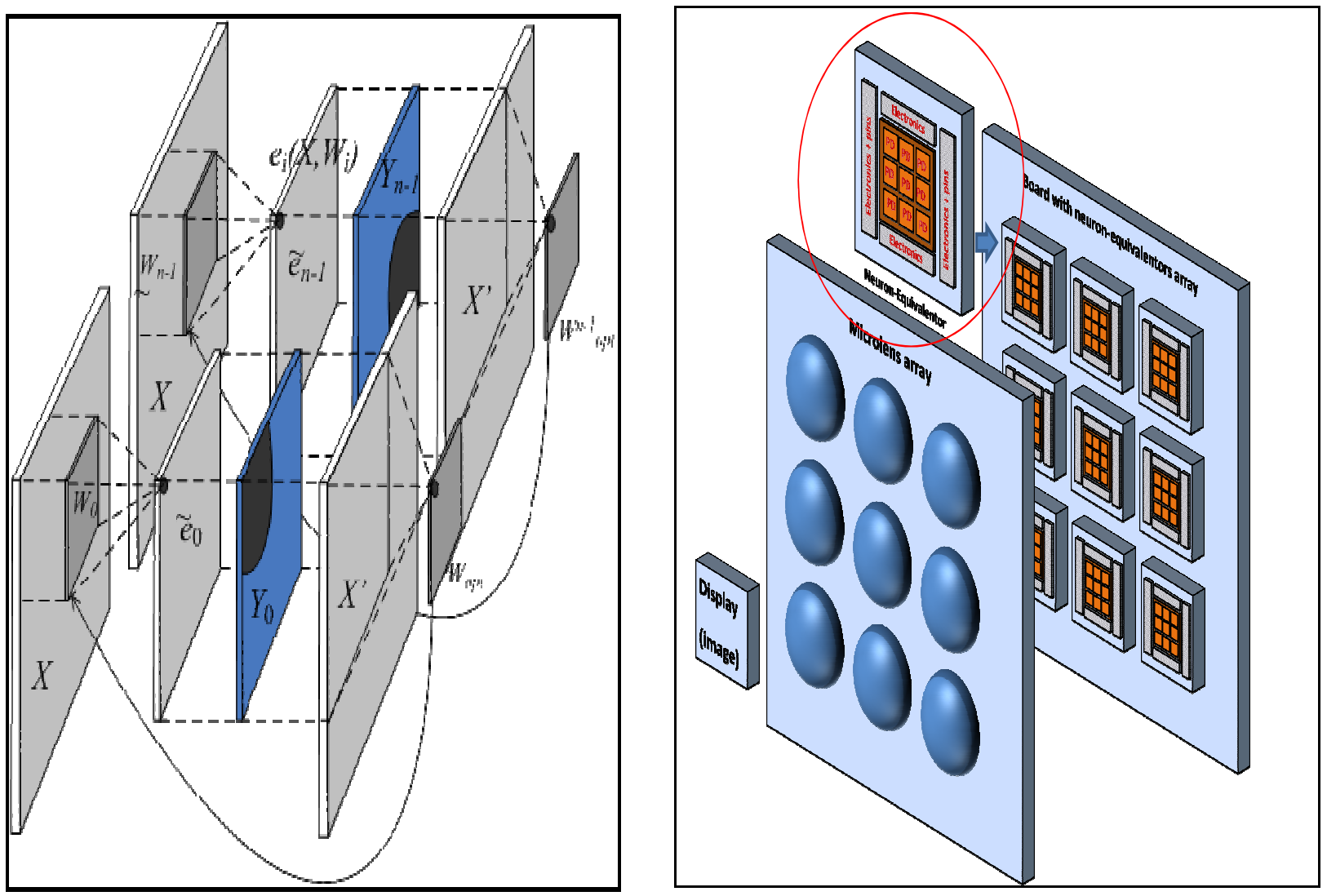

Fig. 1. The structure of the basic unit of the SLECNS, which explains the principle of its functioning;

Figure explains the principles of learning neural network model based on the multi-port memory to find centroid cluster elements (left). The system structure that uses an array of neuron-equivalentors (right)

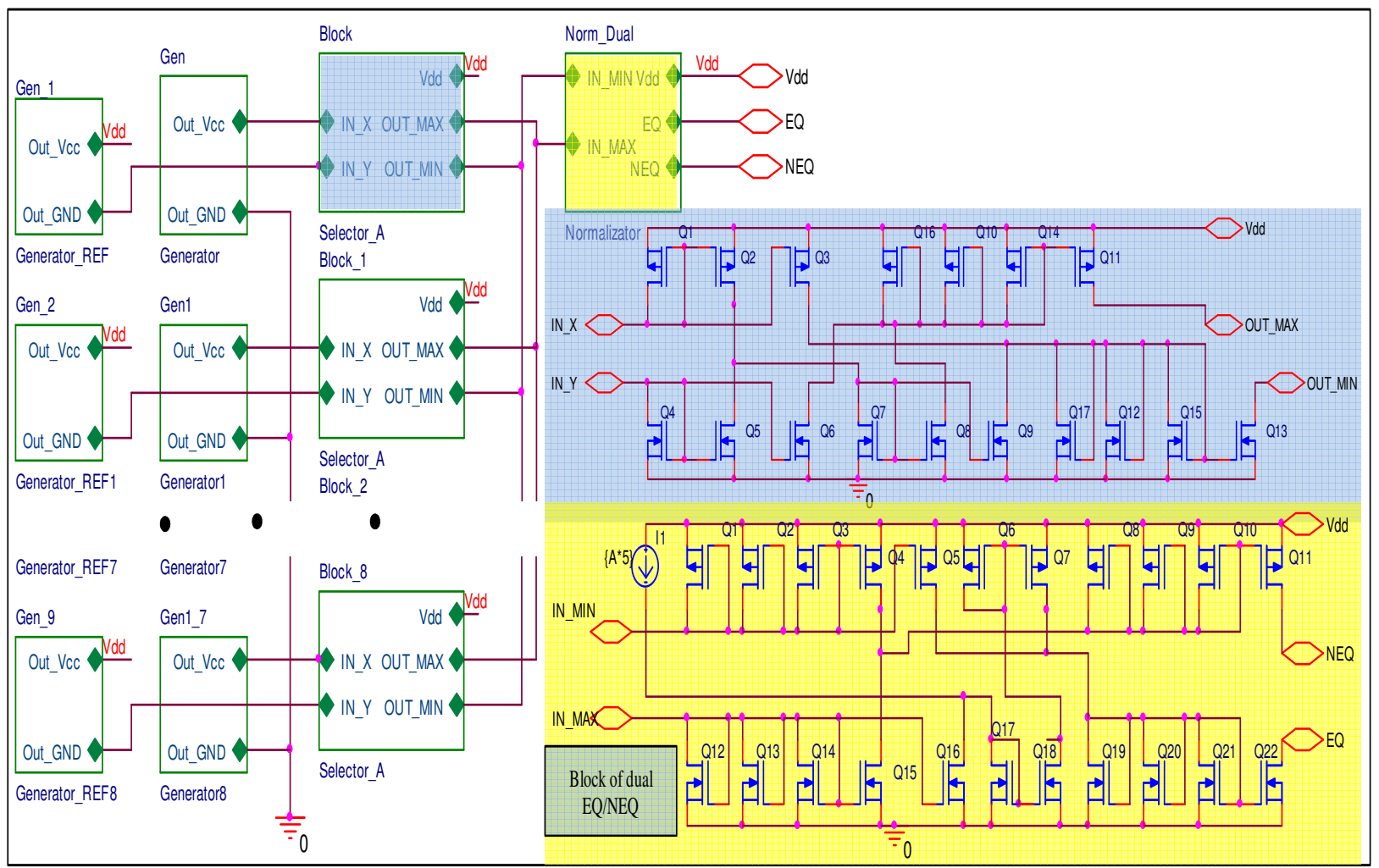

Fig. 2. The basic unit for calculating the normalized Eq (NEq) by averaging the component peak and minima of currents on the basis of current mirrors and the schemes of the limited difference 

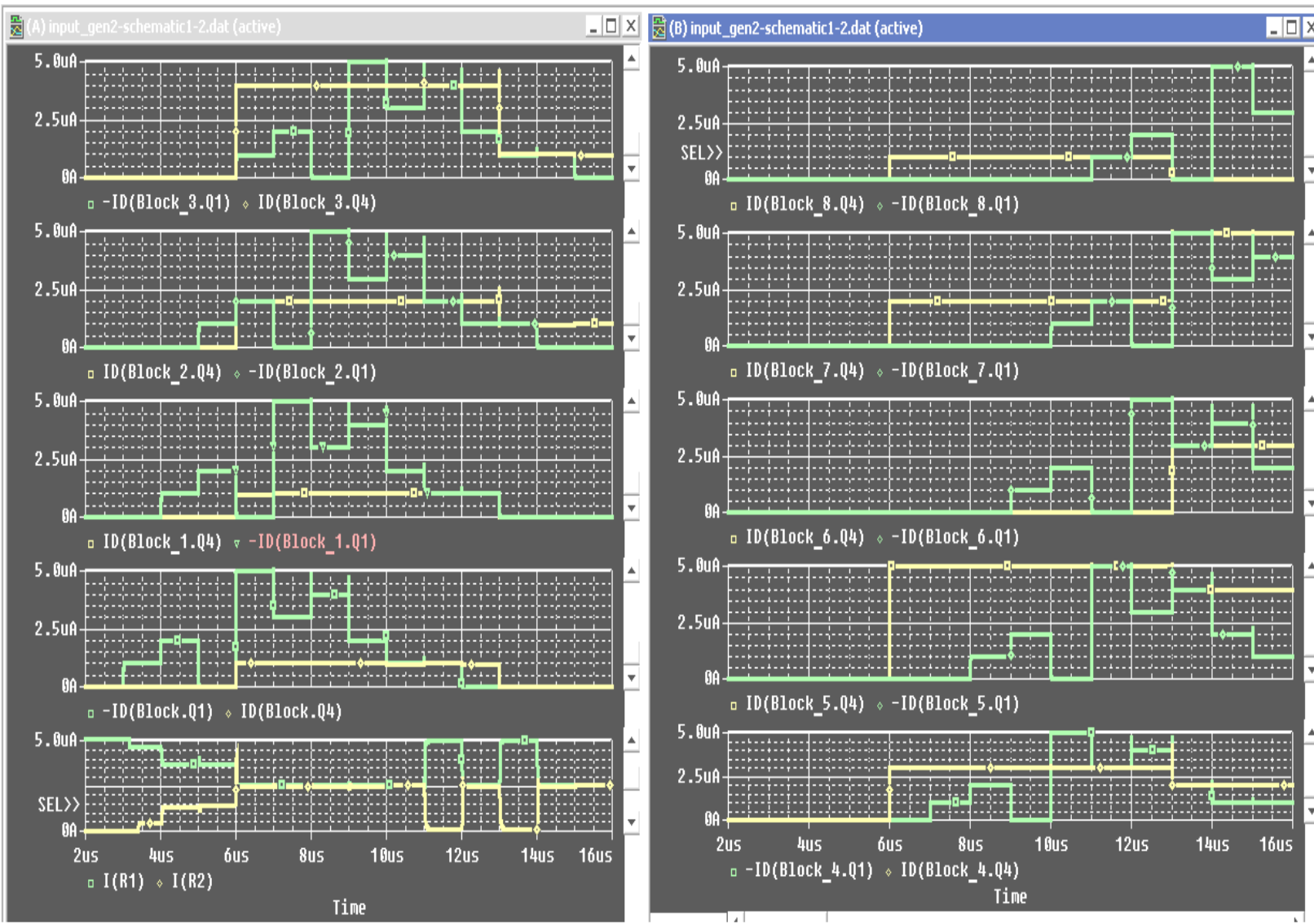

Fig. 3. The results of modeling the base unit for the filter size $3 \times 3$ and for current $\operatorname{Imax}=5 \mu \mathrm{A}, T=1 \mu \mathrm{s}$.

Green shows all 9 input signals, yellow - the signals of the reference filter.

Below - the result: green - equivalence, yellow - nonequivalence
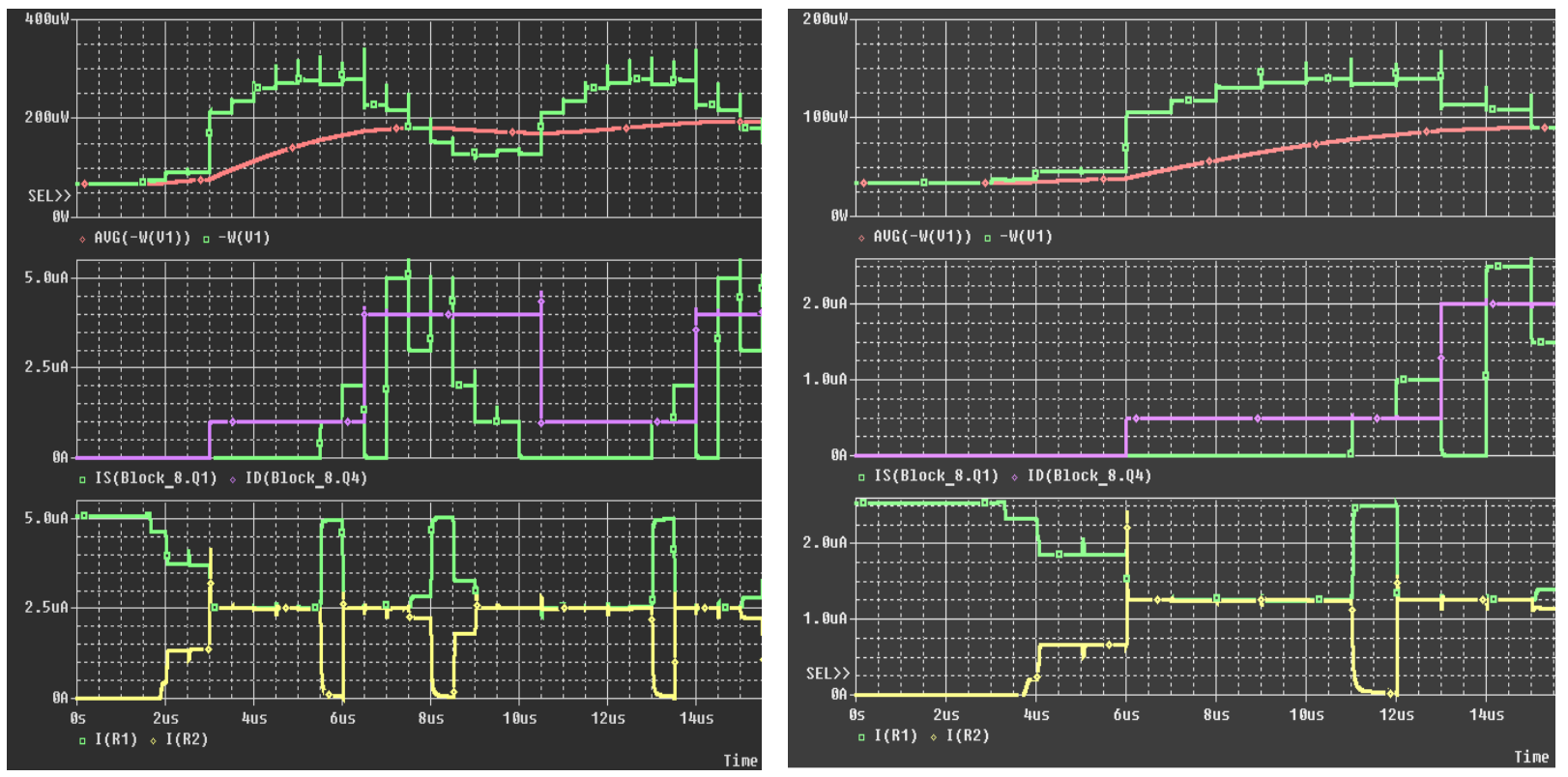

Fig. 4. The results of modeling the base unit for the filter size $3 \times 3$ (with 9 inputs): on the left for current Imax $=5 \mu \mathrm{A}, \mathrm{T}=0.5 \mu \mathrm{s}, \mathrm{V}=1.8 \mathrm{~V}, \mathrm{P}=200 \mu \mathrm{W}$.

On the right for current Imax $=2.5 \mu \mathrm{A}, \mathrm{T}=1 \mu \mathrm{s}, \mathrm{P}=100 \mu \mathrm{W}$.

Red line shows power consumption, input (green) and reference (lilac) signals are showed on the midle graphs, on the bottom graph normalized eq (green) and neq (yellow) are showed 

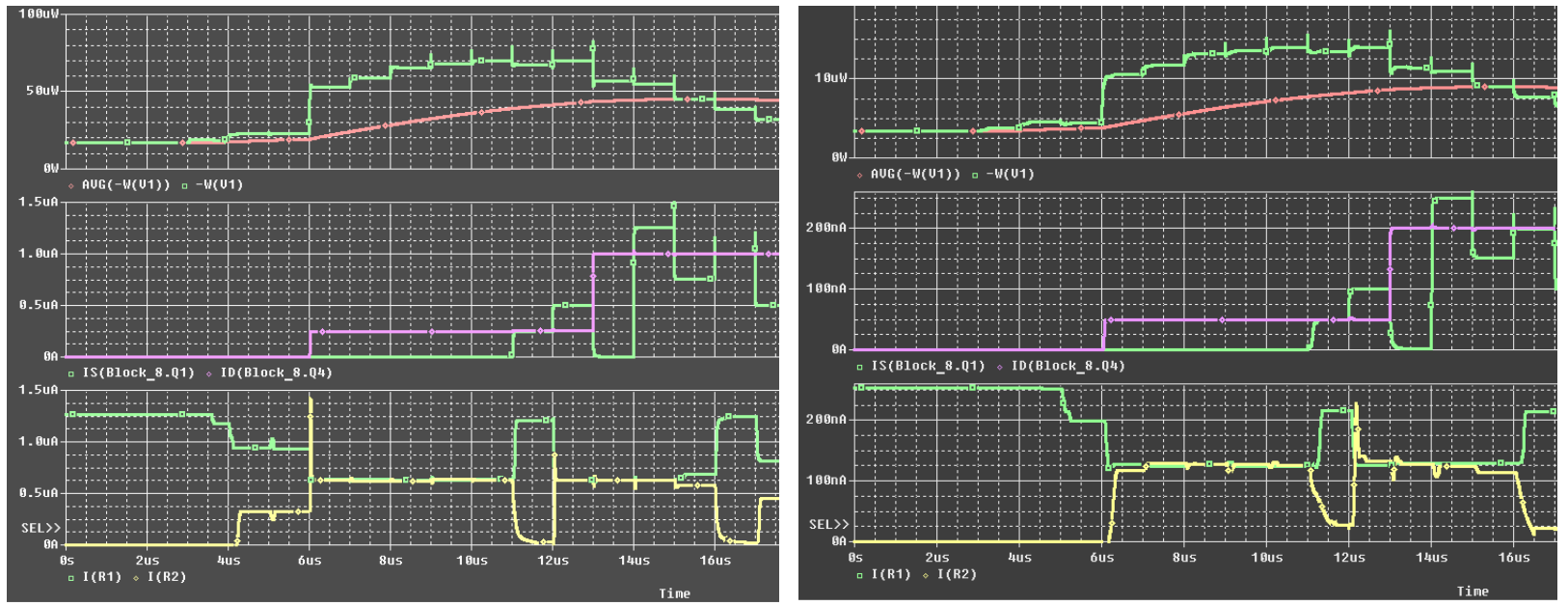

Fig. 5. The results of modeling the base unit for the filter size $3 \times 3$ : (with 9 inputs) on the left for current $I \max =1.25 \mu \mathrm{A}, \mathrm{T}=1 \mu \mathrm{s}, \mathrm{V}=1.8 \mathrm{~V}, \mathrm{P}=50 \mu \mathrm{W}$.

On the right for current Imax $=0.25 \mu \mathrm{A}, \mathrm{T}=1 \mu \mathrm{s}, \mathrm{P}=10 \mu \mathrm{W}$.

Red line shows power consumption, input (green) and reference (lilac) signals are showed on the middle graphs, on the bottom graph normalized eq (green) and neq (yellow) are showed

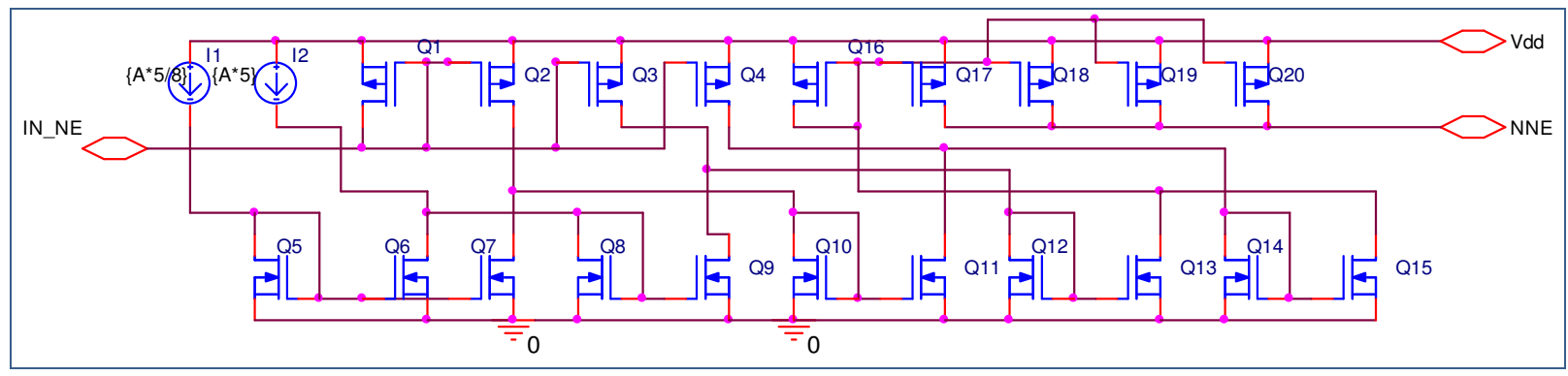

Fig. 6. Activation function circuit on current mirrors

In addition, on the basis of combining nine 9-input NEs, NE was designed and modeled for two 81component inputs, i.e. for convolution by a $9 \times 9$ filter. It has 2 bus analog inputs. Scheme of 81 -input NE with dual outputs is shown in Fig. 11, and the results of its modeling in Fig. 12 and 13.
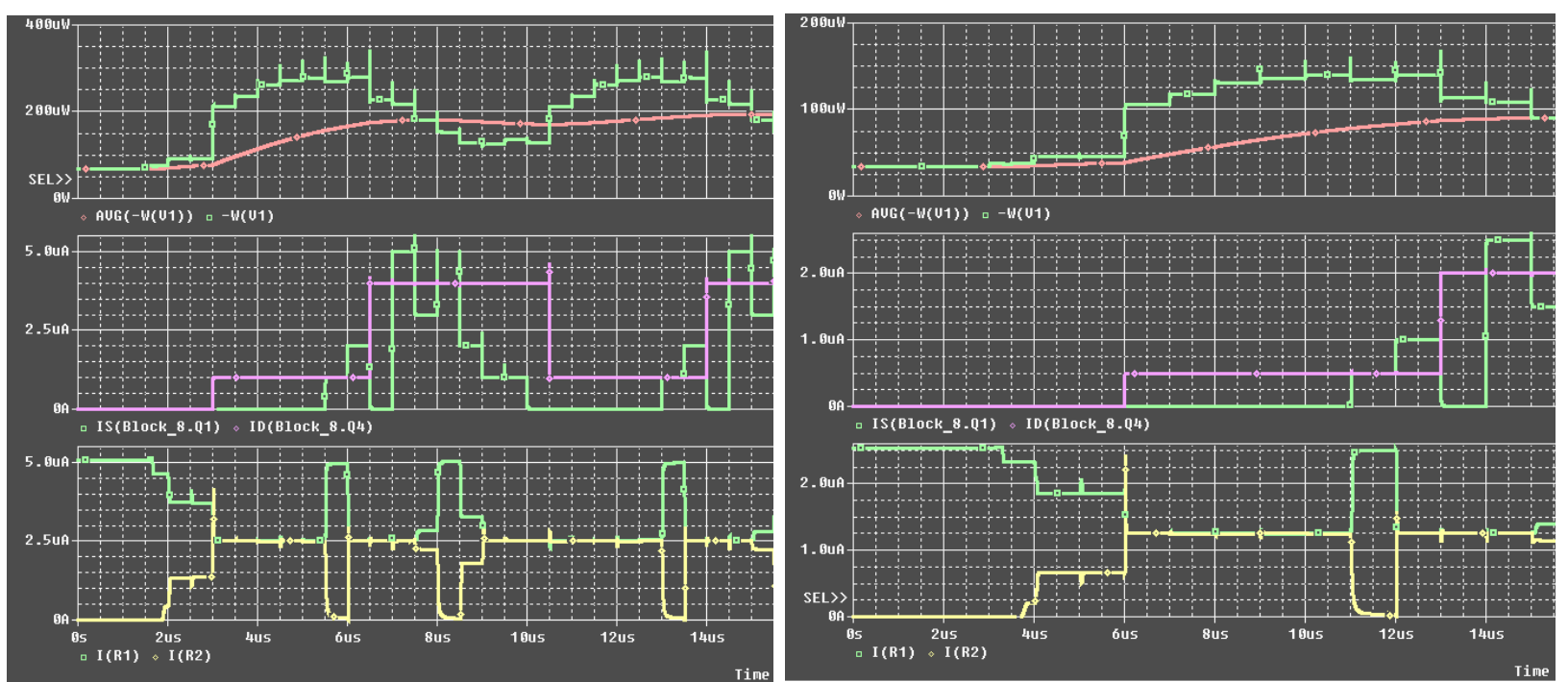

Fig. 7. The results of modeling the base unit for the filter size $3 \times 3$ (with 9 inputs): on the left for current $I \max =5 \mu \mathrm{A}, \mathrm{T}=0.5 \mu \mathrm{s}, \mathrm{V}=1.8 \mathrm{~V}, \mathrm{P}=200 \mu \mathrm{W}$.

On the right for current $\operatorname{Imax}=2.5 \mu \mathrm{A}, \mathrm{T}=1 \mu \mathrm{s}, \mathrm{P}=100 \mu \mathrm{W}$.

Red line shows power consumption, input (green) and reference (lilac) signals are showed on the middle graphs, on the bottom graph normalized eq (green) and neq (yellow) are showed 

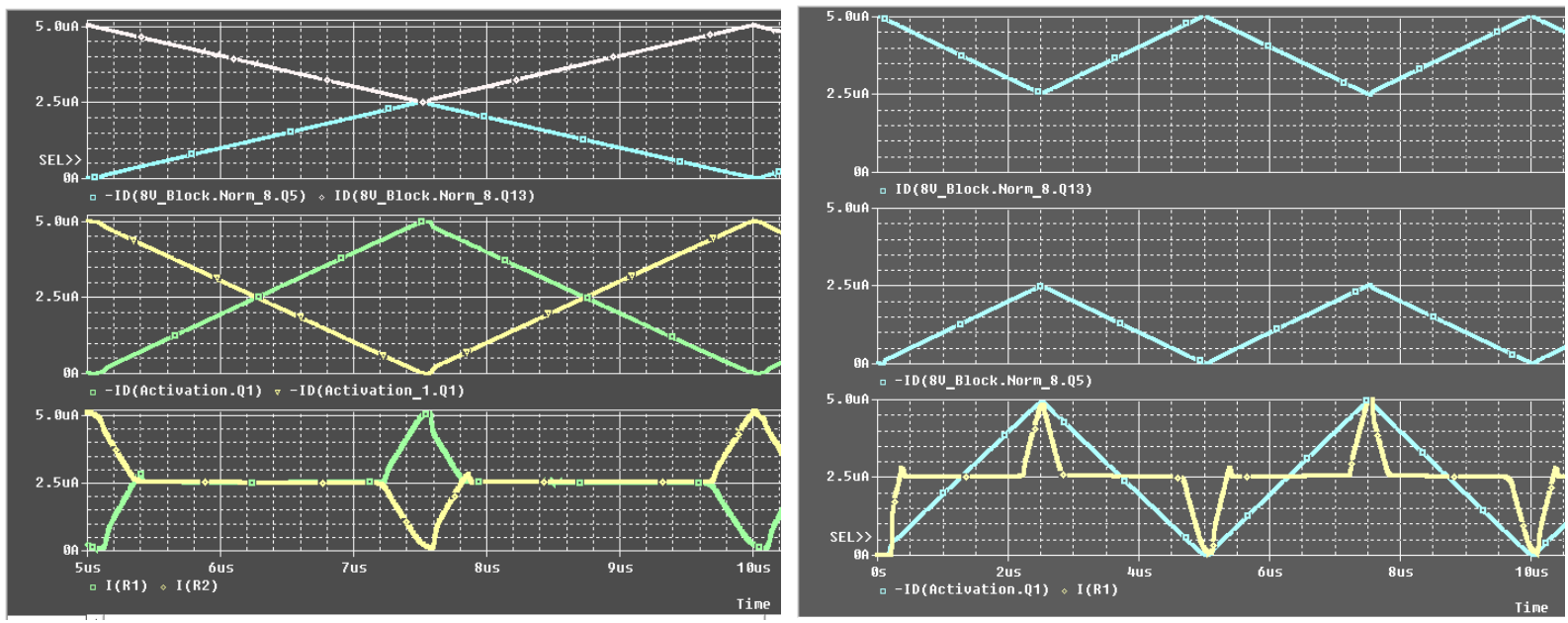

Fig. 8. The results of modeling the NE for the filter size $8 * 8$ and for current Imax $=5 \mu \mathrm{A}$, and a linearly rising (falling) currents with a period $\mathrm{T}=2.5 \mu \mathrm{s}$.

On the left two upper signals (pink - maximum, blue - minimum of two input currents), green - equivalent signal, yellow - nonequivalence, below the signals after their nonlinear conversion; on the right, the two upper signals are the maximum and minimum,

the lower the blue is the normalized equivalence, the yellow is the nonlinear normalized equivalence

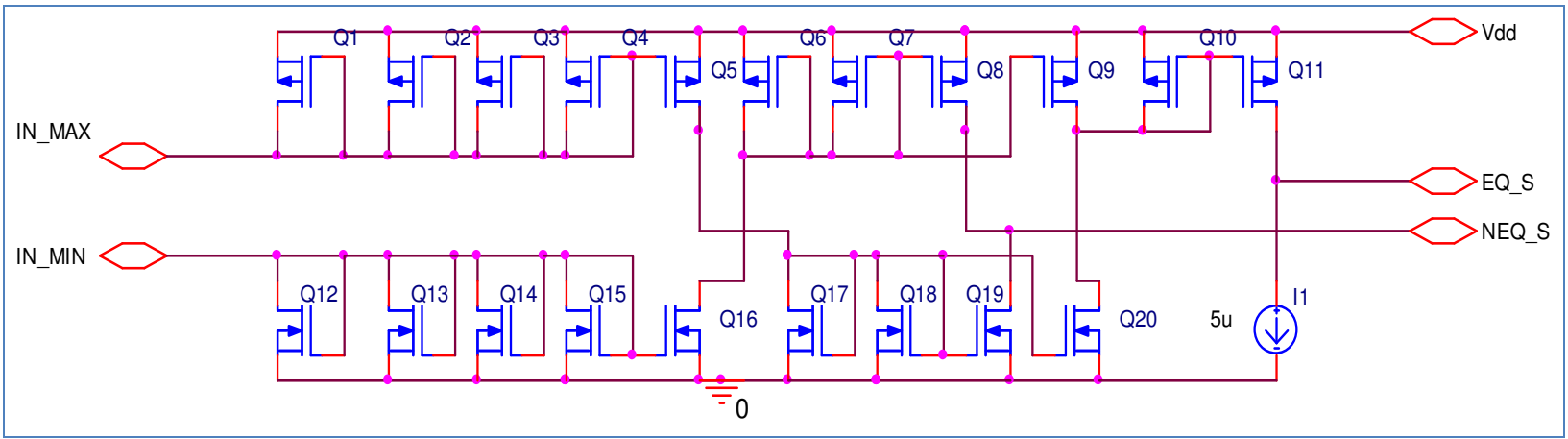

Fig. 9. Circuit of calculator of normalized eq (in the diagram EQ_S)

and neq (in the diagram NEQ_S) with dividers of 8 (for 4 and 2)

based on current mirrors ( 20 transistors when simulating a really 12 )

to level the level when building NEs with 64 component inputs based on 8 basic units
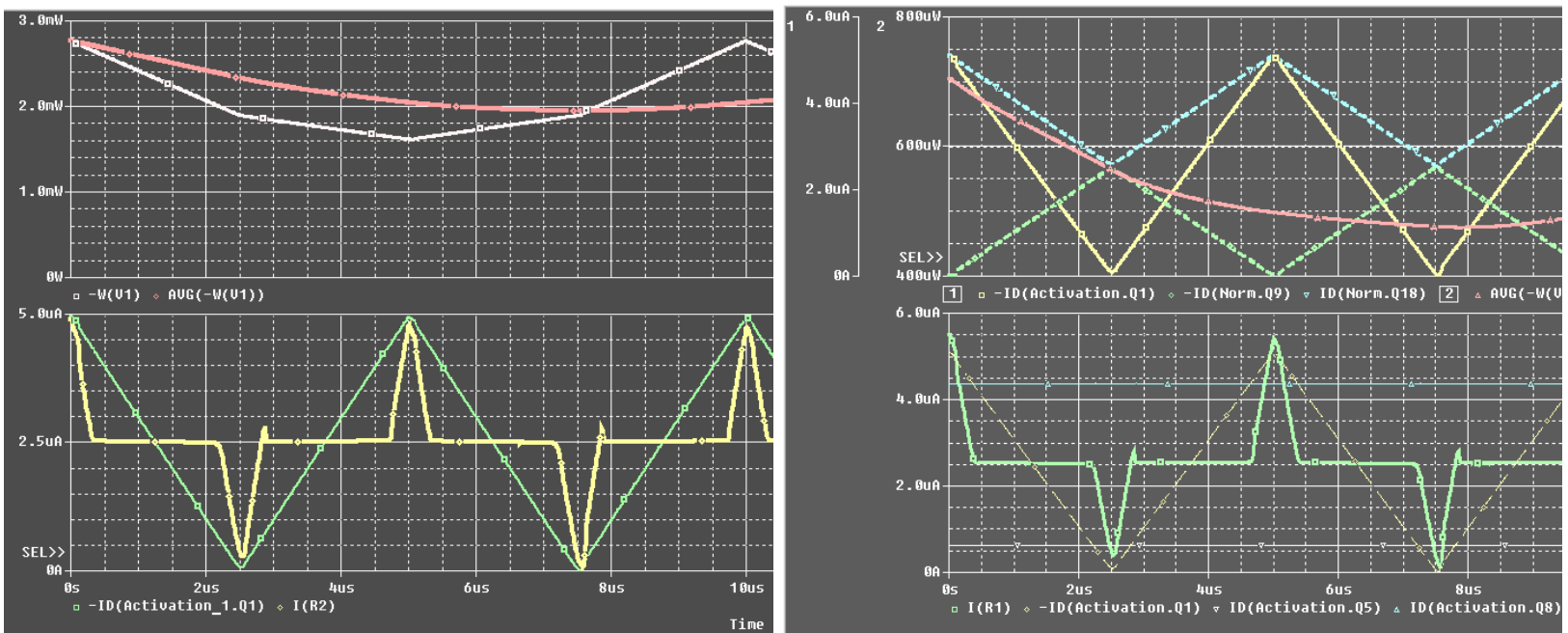

Fig. 10. The results of modeling the $\mathrm{NE}$ for the filter size $8 * 8$ and for current $\operatorname{Imax}=5 \mu \mathrm{A}$, and a linearly rising (falling) currents with a period $\mathrm{T}=2.5 \mu \mathrm{s}$.

On the left: the results of modeling the processes of formation of linear (green) and nonlinear normalized neqs (yellow), on the upper graph the peak and average consumption powers are showed. On the right: the results of modeling the processes of formation of linear (yellow on the upper trace) and nonlinear normalized neqs (green on the bottom trace),

red line shows the power of consumption. Blue - maximum of two signals, green - minimum of two signals for $\mathrm{V}=\mathbf{3 . 3 \mathrm { V }}$ 


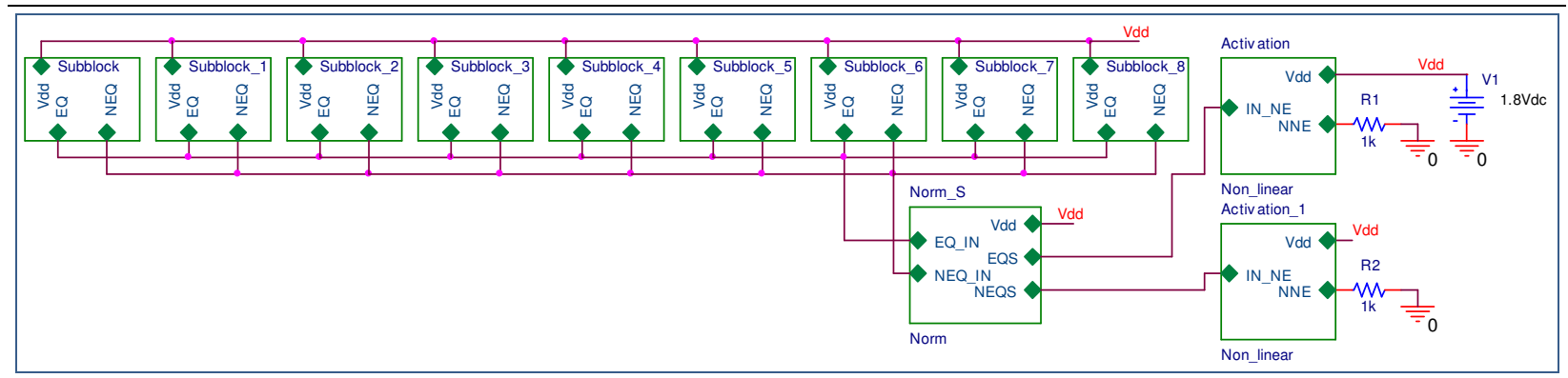

Fig. 11. Scheme of 81-input NE with dual outputs based on 9 basic units for computing normalized eq

(in the diagram EQS) and neg (in the diagram NEQS)

and their transformed responses (NNE outputs of activation circuits)
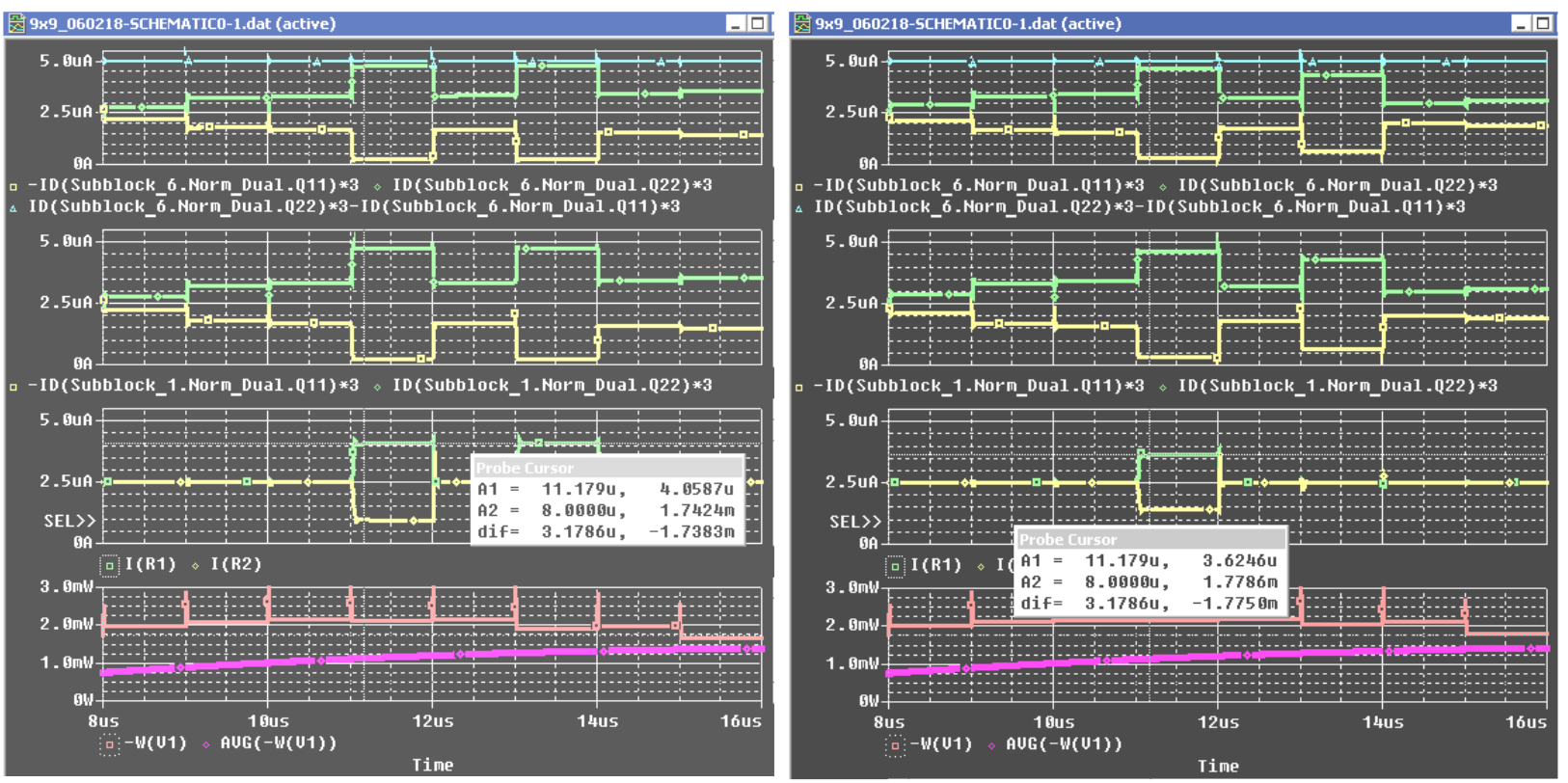

Fig. 12. The results of modeling the 81-inputs HЭ for the filter size $9 \times 9$ (with 81 inputs) for current Imax $=5 \mu \mathrm{A}, \mathrm{T}=1 \mu \mathrm{s}, \mathrm{V}=1.8 \mathrm{~V}, \mathrm{P}=1-2 \mathrm{~mW}$ (bottom):

on the left and right when comparing different input arrays (the measured levels are shown), green and yellow are the dual outputs of the sub-blocks and the entire NE
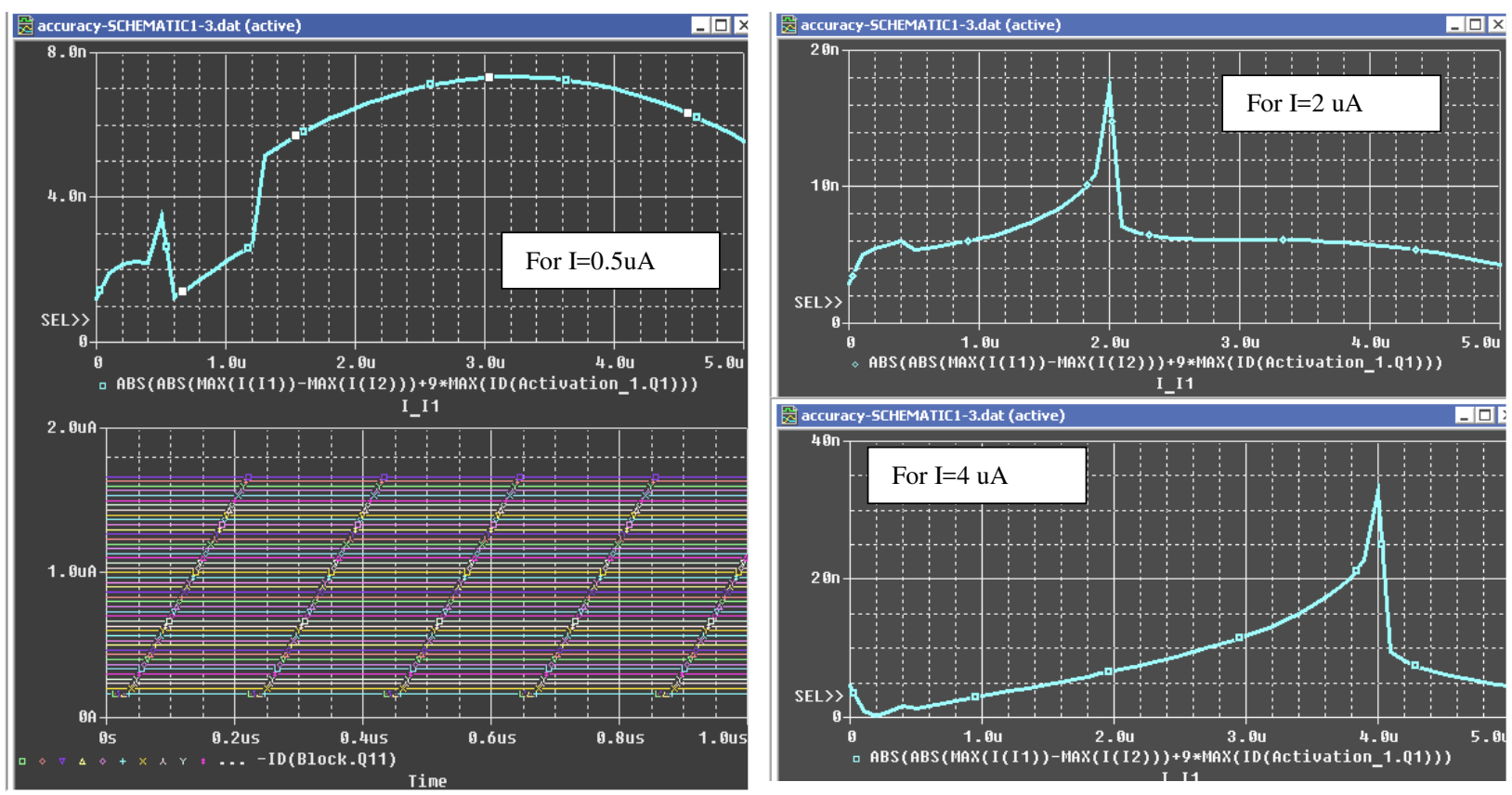

Fig. 13. The result of the calculation accuracy check for normalized eq for various reference DC currents with linearly increasing currents at the second vector inputs (for $\operatorname{Imax}=5 \mu \mathrm{A}, \mathrm{T}=1 \mu \mathrm{s}, \mathrm{V}=1.8 \mathrm{~V}$ ) 
As can be seen from the Fig. 3-5, 7, 8, 10, only at the moments of coincidence of the input current vector with one of the reference template vectors of currents at the output of the neural equivalent appear the required signals, correctly formed with the corresponding high and low levels, reflecting the proximity (equivalence) and distance (nonequivalence) of the compared vectors.

As can be seen from Fig. 13, the maximum deviations of the generated values of the currents at the NE outputs from the mathematically calculated required values do not exceed $50 \mathrm{nA}$, which corresponds to a relative error at the level of $1 \%$ and allows to hope for the possibility of obtaining, in the produced NEs, taking into account technological dispersion, no more than $5 \%$.

For preliminary rough definitions of neuron-winners in neural and CNN networks this is enough. In addition, as will be shown below, non-linear component-wise transformations allow even without WTA network to allocate the most NEs with the greatest activity. To verify the functioning of the developed neural network elements in the network, a mini-network of eight elements with 9 inputs was also created and modeled, the simulation results of which confirmed the correct operation of both the elements and the entire network. To test the functioning of the developed NEs within the network, we created a mini-network of eight 9-input NEs, shown in Fig. 14. And the results of modeling it are shown in Fig. 15, 16.

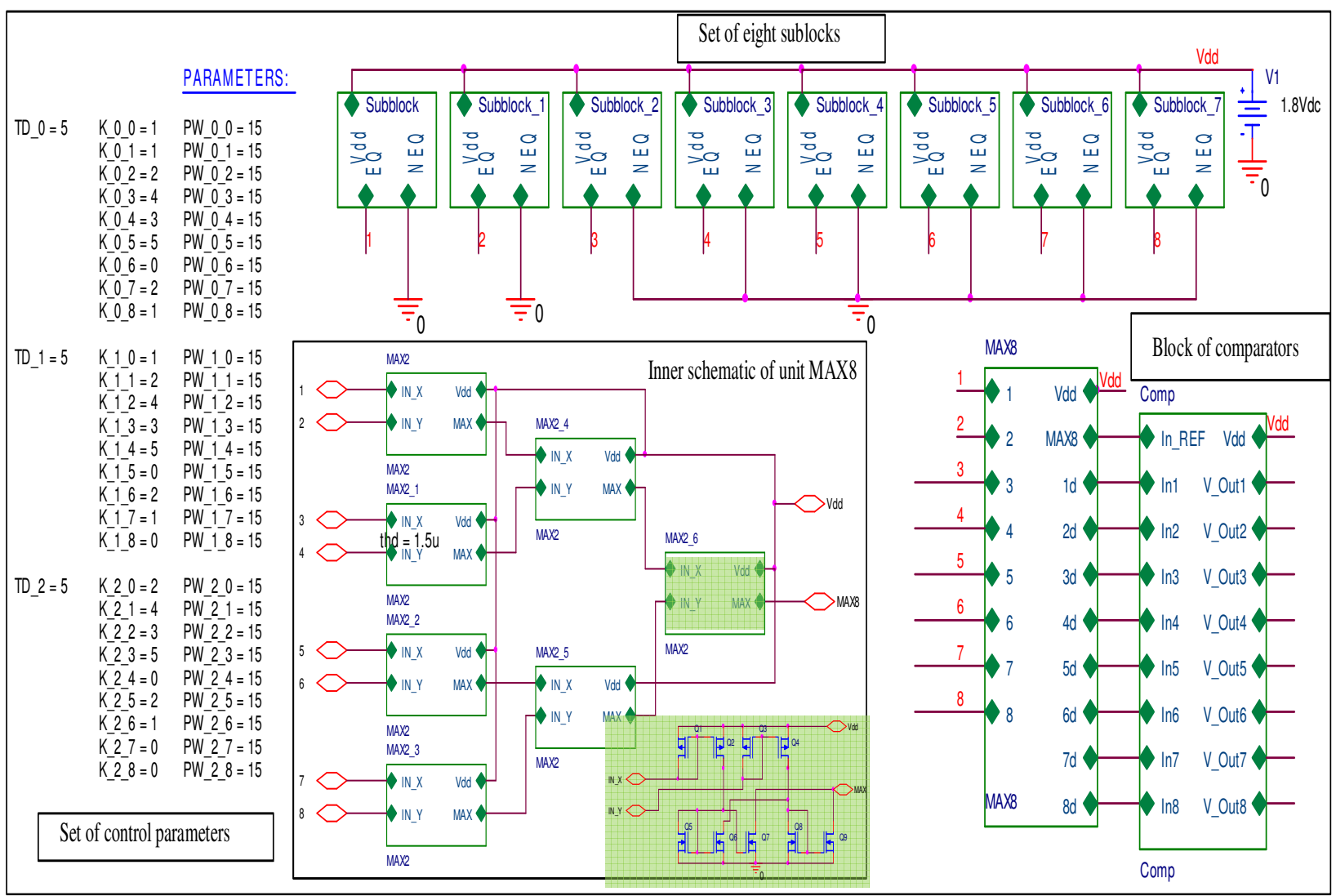

Fig. 14. A network of 89 input NEs based on 9 basic modules for calculating the normalized eq (neq)

Simulation in different modes has shown that the base unit (9-input NE) can operate correctly in low-power modes (1st and 2nd) and high-speed modes (3rd, 4th):

1) $\operatorname{Imax}=0,5 \mu \mathrm{A}, \mathrm{T}=1 \mu \mathrm{s}, \mathrm{Vdd}=1.8 \mathrm{~V},(\mathrm{P}=20 \mu \mathrm{W})$;

2) $\operatorname{Imax}=0,25 \mu \mathrm{A}, \mathrm{T}=2,5 \mu \mathrm{s}, \mathrm{Vdd}=1.8 \mathrm{~V},(\mathrm{P}=10 \mu \mathrm{W})$;

3) $\operatorname{Imax}=5 \mu \mathrm{A}, \mathrm{T}=0,1 \mu \mathrm{s}, \mathrm{Vdd}=1.8 \mathrm{~V},(\mathrm{P}=200 \mu \mathrm{W})$;

4) $\operatorname{Imax}=10 \mu \mathrm{A}, \mathrm{T}=0,05 \mu \mathrm{s},(\mathrm{P}=500 \mu \mathrm{W})$.

If we take into account that at least 20 analog operations $(9 \cdot 2$ comparisons by limited subtractions, current additions, their divisions and nonlinear transformations (2)) are performed by the NE for the one tact $\mathrm{T}$, the relative to the energy efficiency of NEs is estimated to be not less than $20 \cdot 10^{6}$ an. op. $/ \mathrm{sec}: 20 \mu \mathrm{W}=10^{12}$ an. op / sec per W and can be increased by an order.

We modeled on $1.5 \mu \mathrm{m} \mathrm{CMOS}$, and therefore, especially considering the produced FPAA [36], there are all possibilities for this, but much depends on the accuracy of the current mirrors and their characteristics. The analysis of the obtained results confirms the correctness of the chosen concept and the possibility of creating NE and MIMO structures on their basis, as hardware accelerators for compact high-performance systems of machine vision, CNN and self-learning biologically inspired devices. 


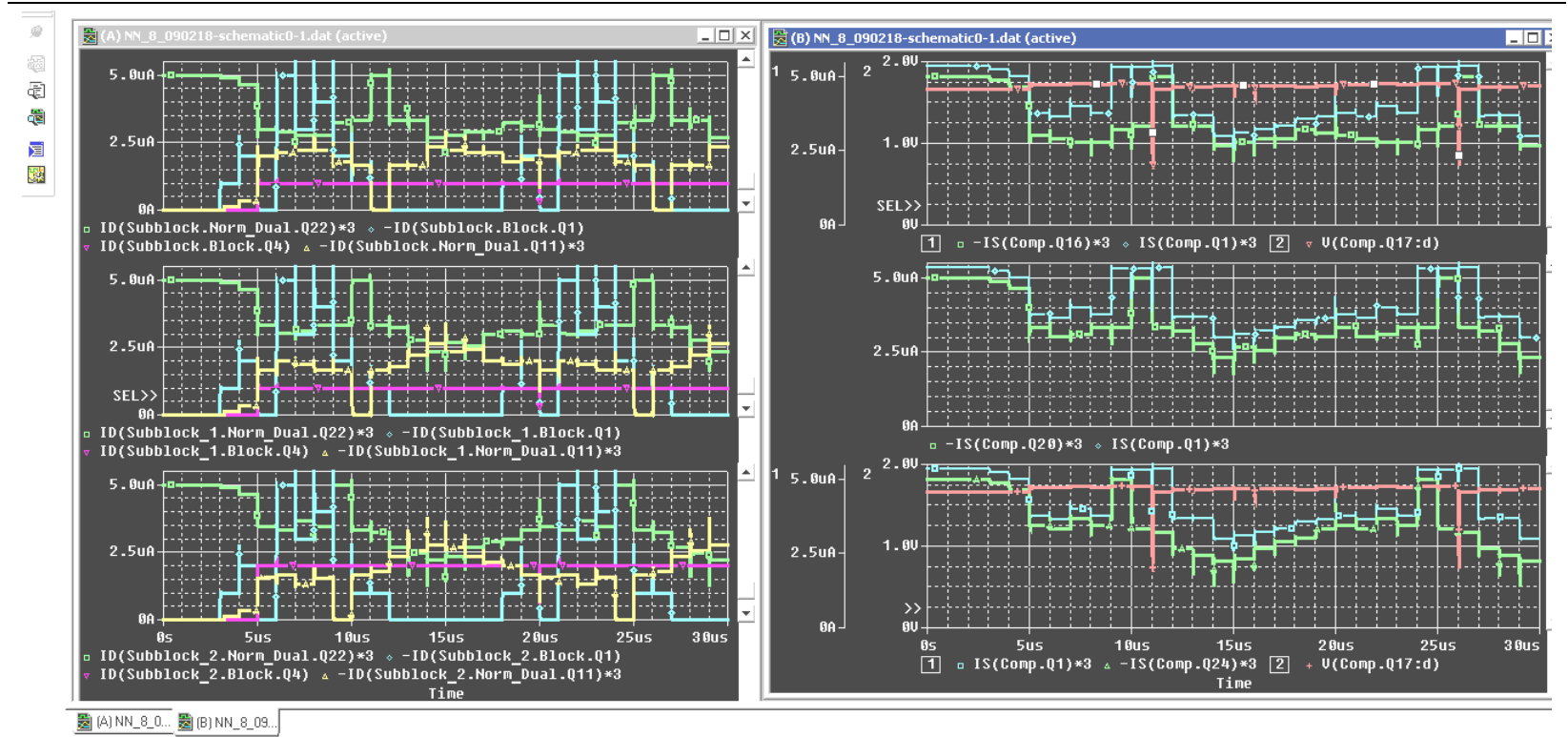

Fig. 15. The result of a network simulation of 89 -input NEs,

a fragment of the successive activity of three neighboring NEs

(three graphs on the left and right) with dual outputs (green -eq and yellow-neq)
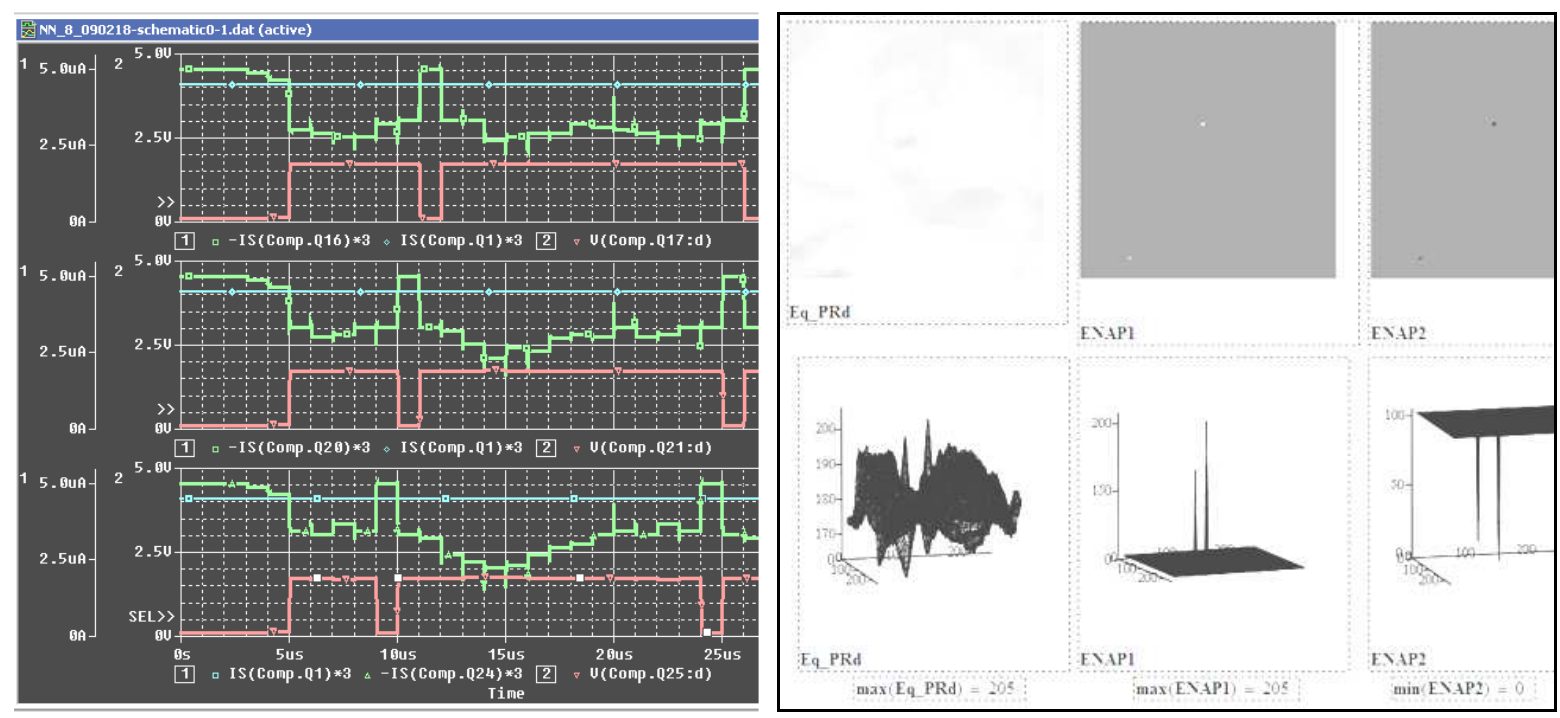

Fig. 16. On the left: The result of a network simulation of 8 9-input NEs, a fragment of the successive activity of three neighboring NEs, green - current outputs, blue-additional threshold, red-NE outputs (voltage, potential).

On the right: The Mathcad windows on which the module of the program with formulas and results of recognition of fragments on the image are shown,

where in 2D and 3D from left to right: the computed NE equivalent, non-linear (after activation) equivalent, linear non- equivalent (part) functions

The figure also shows the Mathcad windows, which display the results of our modeling of the processes of recognizing fragments in the image using the proposed elements based on equivalence models, where in 2D and 3D from left to right: the calculated NE equivalent, nonlinear (after activation) equivalent, linear non-equivalent (partial) functions. The pronounced peaks up and down for the complementarity of functions show an improvement in discriminant capabilities with nonlinear processing compared to simple processing.

\section{Summary}

Optoelectronic complement dual analog neuron-equivalentors (Nes) as hardware accelerators of selflearning equivalent-convolutional neural structures (SLECNS) are designed and modeled. The proposed NEs have a modular hierarchical construction principle and are easily scaled. Based on the base units, 64-input and 81-input NEs were designed and modeled, and their main characteristics were measured. It is shown that neuronequivalentors allow one-to-one comparison of two data sets represented as continuous current signals and calculate the measure of their proximity (range) in the form of normalized non-linear equivalence (nonequivalence) using continuous-logic functions of limited difference, determination of maximum and minimum. NEs have a processingconversion time of $0.1-1 \mu \mathrm{s}$, low supply voltages of $1.8-3.3 \mathrm{~V}$, minor relative computational errors (1-5 \%), small consumptions of no more than $1-2 \mathrm{~mW}$, can operate in low-power modes less than $100 \mu \mathrm{W})$ and high-speed $(10-20 \mathrm{MHz})$ modes. The efficiency of NEs relative to the energy intensity is estimated at a value of not less than $10^{12} \mathrm{an}$. op. / sec 
on $\mathrm{W}$ and can be increased by an order of magnitude. The obtained results confirm the correctness of the chosen concept and the possibility of creating NE and MIMO structures on their basis. They can become the basis for the implementation of CNN and self-learning biologically inspired devices with the number of such NEs equal to 1000 , to realize the parallel calculation of equivalent convolutions with filter sizes up to $32 \cdot 32$.

\section{References}

1. Krasilenko, V. G., Saletsky, F. M., Yatskovsky, V. I., Konate, K., "Continuous logic equivalence models of Hamming neural network architectures with adaptive-correlated weighting," Proceedings of SPIE Vol. 3402, pp. 398-408 (1998).

2. Krasilenko, V. G., Magas, A. T., "Multiport optical associative memory based on matrix-matrix equivalentors," Proc. of SPIE Vol. 3055, pp. 137 - 146.

3. Красиленко В. Г. Експериментальні дослідження просторово-інваріантних еквівалентністних моделей асоціативної та гетероасоціативної пам'яті 2D образів / В. Г. Красиленко, Д. В. Нікітович // Системи обробки інформації. - 2014. - Вип. 4. - С. 113-120. - Режим доступу: http://nbuv.gov.ua/UJRN/ soi_2014_4_25.

4. Krasilenko, V. G, "Research and design of equivalence model of heteroasociative memory," The Scientific session of MIFI-2010 Vol.2, pp.83-90.

5. Krasilenko, V. G., Lazarev, A., Grabovlyak, S., "Design and simulation of a multiport neural network heteroassociative memory for optical pattern recognitions," Proc. SPIE Vol. 8398, 83980N-1 (2012).

6. Krasilenko V. G. , Alexander A. Lazarev, Sveta K. Grabovlyak, Diana V. Nikitovich, "Using a multiport architecture of neural-net associative memory based on the equivalency paradigm for parallel cluster image analysis and self-learning," Proc. SPIE Vol. 8662, 86620S (2013).

7. Krasilenko V.G., Nikitovich D.V., "Simulation of self-learning clustering methods for selecting and grouping similar patches, using two-dimensional nonlinear space-invariant models and functions of normalized "equivalence," Electronics and information technologies: collected scientific papers, Lviv: Ivan Franko National University of Lviv, Issue 6, pp. 98-110 (2015). http://elit.lnu.edu.ua/pdf/6_11.pdf .

8. Krasilenko V.G., Lazarev A.A., Nikitovich D.V., "Modeling and possible implementation of selflearning equivalence-convolutional neural structures for auto-encoding-decoding and clusterization of images", Proc. SPIE Vol. 10453, 104532N (2017); https://doi.org/10.1117/12.2276313

9. Krasilenko V.G., Lazarev A.A., Nikitovich D.V., "Modeling of biologically motivated self-learning equival

10. ent-convolutional recurrent-multilayer neural structures (BLM_SL_EC_RMNS) for image fragments clustering and recognition", Proc. SPIE 10609, MIPPR 2017: Pattern Recognition and Computer Vision, 106091D (8 March 2018); doi: 10.1117/12.2285797; https://doi.org/10.1117/12.2285797

11. Krasilenko V.G., Nikolskyy, A. I., "Optical pattern recognition algorithms based on neural-logic equivalent models and demonstration of their prospects and possible implementations," Proc. of SPIE Vol. 4387, pp. 247-260 (2001).

12. Krasilenko, V. G., Kolesnitsky, O. K., \& Boguhvalsky, A. K. "Application of non-linear correlation functions and equivalence models in advanced neuronets," Proc. of SPIE Vol. 3317, pp. 211-223 (1997).

13. Rudenko OG, Bodiansky EV Artificial neural networks. - Kharkov: OOO SMIT Company, 2005. $408 \mathrm{p}$.

14. Krasilenko V.G., Nikolskyy, A. I., Pavlov S. N., "The associative 2D-memories based on matrix-tensor equivalental models", // Radioelektronika. Informatics. Management. - No. 2 (8). - 2002. - P. 45-54.

15. Krasilenko, V. G., Nikolskyy, A. I., Lazarev A.A., Magas T.E., "Design and simulation of optoelectronic complementary dual neural elements for realizing a family of normalized vector 'equivalencenonequivalence' operations," Proceedings of SPIE Vol. 7703, 77030P.

16. Krasilenko V.G., Nikolsky A.I., Lazarev A.A., Sholohov V. I., "The concept of biologically motivated time-pulse information processing for design and construction of multifunctional devices of neural logic," Proc. SPIE Vol. 5421, 183-194, Intelligent Computing: Theory and Applications II, (12 April 2004)

17. Krasilenko V.G., Nikolsky A.I., Yatskovsky V.I., Ogorodnik K. V., Lischenko S., "Family of new operations equivalency of neuro-fuzzy logic: optoelectronic realization and applications," Proc. SPIE 4732, 106120, Photonic and Quantum Technologies for Aerospace Applications IV, (1 August 2002); doi: 10.1117/12.477429

18. Krasilenko, V., Magas, A., "Fundamentals of design of multi-functional devices of matrix multi-valued logic with fast programmed adjusting," Measuring and computer technique in technological processes, 4, 113-121 (1999).

19. Krasilenko, V.G., Nikolsky, A.I., Lazarev, A.A., Michalnichenko, N. N., "Smart time-pulse coding photoconverters as basic components 2D-array logic devices for advanced neural networks and optical computers", Proc. SPIE Vol. 5439, (2004).

20. Krasilenko, V., Nikolskyy, A., Lazarev, A., Pavlov, S., "Design and applications of a family of optoelectronic photocurrent logical elements on the basis of current mirror and comparators," Proc. SPIE 5948, 426435 (2005). 
21. Vladimir G. Krasilenko, Aleksandr I. Nikolskyy, Alexander A. Lazarev, "Designing and simulation smart multifunctional continuous logic device as a basic cell of advanced high-performance sensor systems with MIMOstructure," Proc. SPIE 9450, Photonics, Devices, and Systems VI, 94500N (6 January 2015); doi: $10.1117 / 12.2073893$

22. Krasilenko, V., Ogorodnik, K., Nikolskyy, A., Dubchak, V., "Family of optoelectronic photocurrent reconfigurable universal (or multifunctional) logical elements (OPR ULE) on the basis of continuous logic operations (CLO) and current mirrors (CM), " Proc. SPIE 8001, (2011).

Vladimir KRASILENKO

Nataliya Yurchuk

DIANA NIKITOVICH
ORCID ID: 0000-0001-6528-3150 krasvg@i.ua

ORCID ID: 0000-0002-7987-9390

ORCID ID: 0000-0002-8907-1221 diananikitovych@gmail.com

Рецензія/Peer review : 25.05.2021 p. Надрукована/Printed :30.06.2021 p. 